\title{
Indice general de autores de los números 1-53 (1967-1980)
}

Aberasturi, Marcelo. Asia Oriental y Meridional y el Pacifico: inicios de 1972. Año $v, N^{\circ} 17$ (enero-marzo, 1972).

Acosia, Mercedes y Vilas, Carlos María. Santo Domingo y Checoslovaquia en la politica de bloques. Año II, $N^{\circ} 8$ (eneromarzo, 1969).

Aftalión, Marcelo E. La política exterior norteamericana y América Latina. Año x, $N^{\circ} 37$ (enero-marzo, 1977).

ALCALDE, Javier. Las relaciones económicas internacionales en la década del 80. Año XIV, $N^{\circ} 53$ (enero-marzo, 1981).

ALmeIDA, Rómulo. Reflexiones sobre la integración Latinoamericana. Año XIII, Nº52 (octubre-diciembre, 1980).

AlmeIda, Clodomiro. La OLAS y las crisis políticas de América Latina. Año I, Nos 3-4 (octubre, 1967; marzo, 1968)

ANDRADE, Gustavo. ¿̇Hacia dónde va el Japọn? $\mathrm{N}^{\circ} 43$ (julio-septiembre, 1978).

Araujo Castro, José A. de. El continente americano dentro de la problemática mundial. Año v, $\mathrm{N}^{\circ} 20$ (octubre-diciembre, 1972).

Azeredo da Silveira, Antonio. Las relaciones entre América Latina y los Estados Unidos. Año XII, $\mathrm{N}^{\circ} 45$ (enero-marzo, 1979).

AzIz, Sartaj. Los verdaderos problemas de la crisis de alimentos. Año viII, $N^{\circ} 30$ (abriljunio, 1975).

Baltra, Alberto. América Latina y la Segunda UNCTAD. Año II, $\mathrm{N}^{\circ} 8$ (enero-marzo, 1969).

BALL, W. MacMahon. Australia en el Pacifico. Año v, $\mathrm{N}^{\circ} 20$. (octubre-diciembre, 1972).

BARROS, Raymundo. La elección del parlamento europeo por sufragio universal directo. Año xil, $N^{\circ} 48$ (octubre-diciembre, 1979).
BAMBIRRA, Vania. La revolución cultural y el marxismo. Año II, $N^{\circ} 7$ (octubrediciembre, 1968).

Bergsten, C. Fred. Relaciones económicas entre Estados Unidos y Latinoamérica, la estructura internacional y algunos énfoques posibles. Año viı, $N^{\circ} 31$ (julioseptiembre, 1975).

Relaciones económicas entre los Estados Unidos y América Latina. Año xII, $\mathrm{N}^{\circ} 47$ (julio-septiembre, 1979).

BERNSIEIN, Enrique. Situación política en víspera de mayo de 1968. Año $\mathrm{v}, \mathrm{N}^{\circ} 19$ (julio-septiembre, 1972).

Berrocal, Fernando. América Latina en la década de los 80. $N^{\circ} 49$ (eneromarzo, 1980).

BODENHEIMER, Susanne. La crisis del movimiento socialdemócrata en América Latina. Año IV, $N^{\circ} 12$ (enero-marzo, 1970).

BogNAR, Jozsef. Reforma económica en Hungría. Año trI, N 10 (julio-septiembre, 1969).

Botero, Rodrigo: La Comisión Brandt: una perspectiva latinoamericana. Año xII, $\mathrm{N}^{\circ}$ 48 (octubre-diciembre, 1979).

BULL, Hedley. Las relaciones internacionales como ocupación académica. Año vir, $\mathrm{N}^{\circ} 28$ (octubre-diciembre, 1974).

BURTON, J.W. No-alineación y política mundial contemporánea. Año III, $\mathrm{N}^{\circ} 9$ (abriljunio, 1969).

BYTH, James. Niugini: una nueva nación cuprifera en el Pacífico se acerca a su independencia. Año VI, N²2 (abril-junio, 1973).

Cadena, Cecilia y Joxe, Alain. Armamentismo dependiente: Caso latinoamericano. Año IV, $N^{\circ} 14$ (julio-septiembre, 1970).

Casanova, Manuel. El sistema económico internacional de la postguerra: la participación de América Latina. Año Xı, $\mathrm{N}^{\circ} 46$ (abril-junio 1979). 
CEPEDA, Fernando. La influencia de los organismos internacionales en èl proceso colombiano. Año xI, No 43 (julio-septiembre, 1978).

Chaparro, Patricio. El sistema económico latinoamericano (SELA), como instancia de mediación, representación y acción política, ¿destinado al fracaso? Año xil, $\dot{N}^{\circ} 48$ (octubre-diciembre, 1979).

CIRIA, Alberto. La comunicación política en América Latina: Algunos de sus problemas. Año II, $N^{\circ} 8$ (enero-marzo, 1969).

ClaRKSON, Stephen. La intelligentsia satélite: Los intelectuales canadienses frente a los Estados Unidos. Año v, $\mathrm{N}^{\circ} 18$ (Abriljunio, 1972).

Glaverie Rodriguez, Eliodoro L. EciHev'ERRiA, Pedro Luis y Villalba Vera Jovito A. Tratado modificado de reciprocidad comercial entre Venezuela y los Estados Unidos. Año v, No 19 (julio-septiembre, 1972.)

CONTANTINESCU, Leontín. Las relaciones Estados Unidos-Comunidad Económica Europea en la perspectiva de la Rueda $\mathrm{Ni}$ xon. Año vı, $\mathrm{N}^{\circ} 21$ (enero-marzo, 1973).

CoTler, Julio. Crisis política y Populismo Militar en el Perú. , $\mathrm{N}^{\circ} 12$ (enero-marzo, 1970). Año IV.

CRONER, Claos. Estudios sobre el subdesarrollo colombiano. Comentario crítico. Año IV, $\mathrm{N}^{\circ} 14$ (julio-septiembre, 1970).

DELGADO, Carlos. Sobre algunos problemas de la participación en la Revolución Peruana. Año vi, $N^{\circ} 21$ (enero-marzo, 1973).

Devillers, Philippe. Francia y la Segunda Guerra del Vietnam. Año II, $N^{\circ} 6$ (julioseptiembre, 1968).

Diamand, Marcelo. Las posibilidades de una técnica nacional en Latinoamérica (el caso argentino). Año Ix, $\mathrm{N}^{\circ} 34$ (abril-junio, 1976).

Hacia el cambio del paradigma económico a través de la experiencia de los países en desarrollo. Año $\mathrm{x}, \mathrm{N}^{\circ} 39$ (julioseptiembre, 1977).

DiAz A., Rodrigo. La definición internacional de la agresión. , $\mathrm{N}^{\circ} 43$ (Julioseptiembre, 1978).
El sistema de seguridad interamericana $y$ sus nuevos desarrollos a través del tratado de Tlatelolco. Año Xi11, $\mathrm{N}^{\circ} 51$ (julioseptiembre, 1980).

Diaz Alejandro, Carlos F. El Grupo Andino en el proceso de Integración Latinoamericana. Año $11, \mathrm{~N}^{\circ} 6$ (julio-septiembre, 1968).

Relaciones Norte-Sur. El componente "conómico. Año $\mathrm{x}, \mathrm{N}^{\circ} 37$ (enerc 'arzo, 1977).

Drekonia, Gerhald. Aproximaciones a :a-palítica exterior Latinoamericana. Año XIV, $N^{\circ} 53$ (enero-marzo, 1981).

ECheverria, I dro Luis, Claverie RonRiGuez Heliodoro L., y Villalba Vera, Jovito A. El tratado modificado de rèciprocidad comercial entre Venezuela y los Estados Unidos. Año v, No. 19 (julioseptiembre, 1972).

END, HEINRICH. La politica exterior del gobierno Kissinger-Brandt. Año II, $\mathrm{N}^{\circ} 7$ (octubre-diciembre, 1968).

FAGEN, Richard. La política exterior de los Estados Unidos y el desarrollo del Tercer Mundo. Año 1X, N³5 (julioseptiembre, 1976).

FAÚNDEZ, Julio. El Sistema Interamericano de Seguridad en la política exterior de Estados Unidos. Año 111, $N^{\circ} 11$ (octubrediciembre, 1969).

El presidente de Estados Unidos y' la facultad para hacer la guerra. Año IV, $\mathrm{N}^{\circ} 15$ (octubre-diciembr, 1970).

FERrER, Aldo. Relaciones económicas entre la Comunidad Económica Europea y América Latina. Año VI, N 24 (octubrediciembre, 1973).

La crisis del sistema monetario internacional. Un enfoque estructuralista. Año VIII, $N^{\circ} 30$ (abril-junio, 1975).

La crisis del sistema Trilateral y América Latina. $\mathrm{N}^{\circ} 42$ (abril-junio, 1978).

Fishlow, Albert. Los nuevos intereses de los Estados Unidos en el Hemisferio Occidental. $\mathrm{N}^{\circ} 49$ (enero-marzo, 1980).

La economía internacional desde una perspectiva Latinoamericana. $\mathrm{N}^{\circ} 49$ (eneromarzo, 1980). 
FloRes de LA PEÑA, Horacio. Un nuevo modelo de desarrollo. Año $\mathrm{x}, \mathrm{N}^{\circ} 39$ (julioseptiembre, 1977).

FRENCH Davis, Ricardo. Pacto Andino y libre comercio. Año $\mathrm{x}, \mathrm{N}^{\circ} 38$ (abril-junio, 1977).

FRONDizZI, Arturo. El problema nacional de América Latina y ciertos esquemas de integración regional. Año I, Nos 3 y 4 (octubre, 1967-marzo, 1968).

FOGARTY, John. Australia y el problema de las inversiones extranjeras. Año $\mathrm{VI}, \mathrm{N}^{\circ} 22$ (abril-junio, 1973).

Fuenzalida, Edmundo y Sunkel, Osvaldo. Capitalismo transnacional y desarrollo nacional. $\mathrm{N}^{\circ} 44$ (octubre-diciembre, 1978).

FurTAdo, Gelso. La concentración del poder económico en los Estados Unidos y sus proyecciones en América Latina. Año I, $\mathrm{N}^{\text {os }}$ 3-4 (octubre 1967-marzo, 1968).

El conocimiento económico de América Latina. Año $\mathrm{Ix}, \mathrm{N}^{\circ} 36$ (septiembrediciembre, 1976).

Proceso y frustración de las reformas agrarias en América Latina. Año I, $\mathrm{N}^{\text {os }} 3$ y 4 (octubre, 1967-marzo, 1968).

Una interpretación estructuralista de la "crisis" actual del capitalimo. Año viIr, $\mathrm{N}^{\circ}$ 30 (abril-junio, 1975).

Girvan, Norman. El conflicto de GuyanaALCANy la nacionalización de DEMBA. Año $\mathrm{v}, \mathrm{N}^{\circ} 19$ (julio-septiembre, 1972).

Teorías de dependencia económica en el Caribe y Latinoamérica: un estudio comparativo. Año VI, $\mathrm{N}^{\circ} 23$ (julio-septiembre, 1973).

GrTrings, John. ¿Tiene China una política exterior? Año I, N 1 (abril, 1967),

Libros sobre la guerra en Vietnam. Año $\mathrm{I}$, $\mathrm{N}^{\circ} 2$ (julio, 1967).

El Ejército Popular de Liberación y la Revolución Cultural. Año II, $N^{\circ} 5$ (abriljunio, 1968).

La nueva guerra en Indochina. Año $\mathrm{IV}, \mathrm{N}^{\circ}$ 14 (julio-septiembre, 1970).

GLIGo, Nicolo y otro. Notas sobre la historia ecológica de América Latina. $\mathrm{N}^{\circ} 49$ (enero-marzo, 1980).
Godoy, Horacio H. La integración de América Latina y el proceso del poder mundial. Año If, $\mathrm{N}^{\circ} 17$ (octubre-diciembre, 1968).

Los acuerdos entre los Estados Unidos y la Unión de las Repúblicas Socialistas Soviéticas. Año vIr, $N^{\circ} 28$ (octubre-diciembre, 1974).

Godfrex, Martín y LANGDon, Steven. ¿Socios en el subdesarrollo? El proceso de transnacionalización en el contexto de Kenya. $\mathrm{N}^{\circ}$ 44 (octubre-diciembre, 1978).

GONZÁlEz, Norberto. Prioridades de América Latina en el Diálogo Norte-Sur. $N^{\circ} 47$ (julio-septiembre, 1979).

Go'T, Richard. El sur de Africa y el fin de la guerra fría. Año I, $\mathrm{N}^{\circ}$ I (abril, 1967). El Congo a partir de Mobutu. Año $1, \mathrm{~N}^{\text {os }} 3$ y 4 (octubre, 1967-marzo, 1968).

La experiencia guerrillera en Bolivía. Año II, $\mathrm{N}^{\circ} 5$ (abril-junio, 1968).

Grabendorfa, Wolf. Perspectivas y potos de desarrollo en América Latina. $N^{\circ} 50$ (abiriljunio, 1980).

GRANT, Bruce. Australiay el Pacífico. Año v, $N^{\circ} 17$ (enero-marzo, 1972).

Grant, James P. Las naciones de ta oíep: ¿Asociados o competidores? Año VIII, $\mathrm{N}^{\circ}$ 30 (abril-junio, 1975).

GraYson, George W. Jr. Portugaly el movimiento de las Fuerzas Armadas. Año $\mathrm{IX}, \mathrm{N}^{\circ}$ 33 (enero-marzo 1976).

GREEN, Rosario. La importancia del estudio de las relaciones internacionales de los países Latinoamericanos. Año XIII, No 52 (octubre-diciembre, 1980).

GRIFFITH JONES, Stephany. El crecimiento de la Banca Multinacional. $\mathrm{N}^{\circ} 44$ (octubrediciembre, 1976).

GRUNWALD, Joseph. El comercio intraindustrial Norte-Sur: compartir la producción industrial entre los países en desarrollo y desarrollados. Año XII, $\mathrm{N}^{\circ} 48$ (oetubrediciembre, 1979).

GUERRERo, Mauricio y SAGASTI, Francisco. Situación de la Ciencia y Tecnología en América Latina. Año VII, $\mathrm{N}^{\circ} 25$ (eneromarzo, 1974). 
Halty Garrere, Máximo. ïHacia un muevo orden tecnológico. Año VIII, $\mathrm{N}^{\circ} 32$ (octubre-diciembre, 1975).

HANSEN, Roger. Relaciones económicas entre los Estados Unidos y América Latina ¿̨Bilaterales, regionales o globales? Año vin, $\mathrm{N}^{\circ}$ 31 (julio-septiembre, 1975).

UL HAG, Mahabu. El Diálogo Norte-Sur: la segunda fase. Año $\mathrm{xI}, \mathrm{N}^{\circ} 41$ (eneromarzo, 1978).

HerRera, Amílcar O. La ciencia en el desarrollo de América Latina. Año $11, \mathrm{~N}^{\circ} 5$ (abril-junio, 1968).

Herrera, Felipe. Viabilidad de una comunidad latinoamericana. Año 1, $N^{0} 1$ (abril, 1967).

La tarea inconclusa: América Latina integrada. Año vi, $\mathrm{N}^{\circ} 21$ (enero-marzo, 1973).

América Latina y el desafio internacional - para la educación. Año vil, $N^{\circ} 25$ (eneromarzo, 1974).

América Latina y el Tercer Mundo. Añox, $\mathrm{N}^{\circ} 40$ (octubre-diciembre, 1977).

Las politicas culturales de América Latina. Año XI, N" 43 (julio-septiembre, 1979).

Hirschman, Albert O. Liderazgo, percepción del cambio y subdesarrollo. Año $11, \mathrm{~N}^{\alpha} 6$ (julio-septiembre, 1968).

HODARA, Joseph. La estructura internacional: cuatro visiones. Año vIII, $\mathrm{N}^{\circ} 31$ (julio-septiembre, 1975).

HoFrMaN, Stanley. El estilo norteamericano: su pasado, sus principios. Año $111, N^{\circ} 9$ (abril-junio, 1969).

HolbrAAD, Carsten. Elpapel de las potencias medias en la política intemacional. Añov, $\mathrm{N}^{0} 17$ (enero-marzo, 1972).

HuRTADo, Héctor; PAzos, Javier y MAYoBRE, Eduardo. El Caribe y Venezuela: integración de la integración. Año VII, $\mathrm{N}^{\circ} 27$ (julio-septiembre, 1974).

IGLESIAS, Enrique V. Transferencia de recursos en el ámbito internacional. Año IX, $\mathrm{N}^{\circ}$ 34 (abril-junio, 1976).

Perspectivas económicas de América Latina y sus implicancias para los Estados Unidos. Año XII, $\mathrm{N}^{\circ} 45$ (enero-marzo, 1979). Situación y perspectivas de América Latina.
Año X, N 39 (julio-septiembre, 1977). ¿Va América Latina hacia la Bancarrota? Año XI, No 42 (abril-junio, 1978).

IMAZ, José Luis de. ¿Adiós a la teoría de la dependencia? Una perspectiva desde la Argentina. Año Vil, $\mathrm{N}^{\circ} 28$ (octubrediciembre, 1974).

IRELAND, Rowan. La Iglesia Católica del Brasil: limites del aggiornamiento. Año vII, $\mathrm{N}^{\circ}$ 27 (julio-septiembre, 1974).

JAGUARIBE, Helio. El equilibrio ecológico mundial y los países subdesarrollados. Año $v, \mathrm{~N}^{\circ} 17$ (enero-marzo, 1972).

Los acontecimientos chilenos. Año vil, $\mathrm{N}^{\circ}$ 26 (abril-junio, 1974).

Brasil y la América Latina. Año vıı, $N^{\circ}$ 29 (enero-marzo, 1975).

El Vietnam y los Estados Unidos. Año vil, $\mathrm{N}^{\circ} 31$ (julio-septiembre, 1975).

El estudio del futuro y de la supervivensin. del hombre. Año Ix, $N^{\circ} 36$ (septiembrediciembre, 1976).

El informe Linowitz y las relaciones Estados Unidos-América. Año X, $\mathrm{N}^{\circ} 40$ (octubrediciembre, 1977).

Autonomía perifêrica y hegemonía céntrica. Año xIl, $\mathrm{N}^{\circ} 46$ (abril-junio, 1979).

Joxe, Alain. Hacia una nueva concepción de la seguridad europea. Año I, $N^{\circ} 2$ (julio, 1967).

Cohetes anticohetes: $\dot{\mathrm{G}}$ Regreso a estrategias defensivas? Año $11, \mathrm{~N}^{\circ} 5$ (abril-junio; 1968).

Doctrina estratégica y guerras de intervención. Año II, $N^{\circ} 6$ (julio-septiembre, 1968).

Fin de la preponderancia estratégica norteamericana? Año $11, \mathrm{~N}^{\circ} \mathrm{Il}$ (octubrediciembre, 1968).

JOXE, Alain y CADENA, Gecilia. Armamentismo dependiente: Caso latinoamericano. Año IV, $N^{\circ} 14$ (julio-septiembre, 1970).

KADAR, Bela. Los paises pequeños en la economía mundial. Año IV, $\mathrm{N}^{\circ} 16$ (eneromarzo, 1971).

KAISER, Karl. Una nueva politica oriental en Alemania. Año II, $\mathrm{N}^{\mathrm{O}} 8$ (enero-marzo, 1969). 
KALECKI, M. y KULA, Marcin. Notas sobre los aspectos sociales y económicos de los "Regimenes Intermedios", el caso de Bolivia. Año IV, $N^{\circ} 15$ (octubre-diciembre, 1970).

KÑAKAL, Jan. Las empresas transnacionales en el desarrollo contemporáneo de América Latina. Año XII, $N^{\circ} 47$ (julio-septiembre 1979).

KojIma, Kiyoshi. Un área de libre comercio del Pacífico. Año v, $\mathrm{N}^{\circ} 20$ (octubrediciembre, 1972).

KuLA, Marcin y KaLECKI, M. Notas sobre los aspectos sociales y económicos de los "Regimenes Intermedios"; el caso de Bolivia. Año IV, $\mathrm{N}^{\circ}$ I5 (octubre-diciembre, 1970).

LAFER, Celso. Una redefinición del orden mundial y la Alianza Latinoamericana. Perspectivas y posibilidades. Año vill, $\mathrm{N}^{\circ}$ 31 (julio-septiembre, 1975).

El estudio de las Relaciones Internacionales de América Latina. Año XI, $\mathrm{N}^{\circ} 43$ (julioseptiembre, 1978).

La política exterior brasileña: balance $y$ perspectivas. Año xirr, $N^{\circ} 51$ (julioseptiembre, 1980).

LAGos, Gustavo. El plan Cartery "La Guerra de la Energia". Año $\mathrm{X}, \mathrm{N}^{\circ} 40$ (octubrediciembre, 1977).

Tendencias y perspectivas del estudio de las relaciones internacionales, tarea para América Latina. An̄o XII. $N^{\circ} 50$ (abril-junio, 1980).

LAGOS, Gustavo y Alberto, VAN KLAJEREN. Las relaciones interamericanas en la perspectiva global. Año XII, Nº 48 (octubrediciembre, 1979).

LAGos, Ricardo. América Latina: algunos hechos económicos recientes y su poder de negociación. Año xirl, $\mathrm{N}^{\circ} 51$ (julioseptiembre, 1980).

LANGDON, Steven y GODFREY, Martín. įSocios en el subdesarrollo? El proceso de transnacionalización en el contacto de Kenya. Año XI, $\mathrm{N}^{\circ} 44$ (octubre-diciembre, 1978).

LANGLors, Juan Carlos. Una nueva dimensión para los Bancos de Desarrollo. Año $\mathrm{Lx}$, $\mathrm{N}^{\circ} 33$ (enero-marzo, 1976).
LEVINE, Flavián. ¿Economía o economía politica? Año XII, $\mathrm{N}^{\circ} 47$ (julio-septiembre, 1979).

LowENTHAL, Richard. Alemania y el fin del sistema bipolar en la política intemacional. Año I, Nos 3 y 4 (octubre, 1967-marzo, 1968).

LOWENTHAL, Abraham. Ejércitos y política en América Latina. Año Ix, No 35 (julioseptiembre, 1976).

El fin de la presunción hegemónica. Añox, $\mathrm{N}^{\circ} 37$ (enero-marzo, 1977).

Los nuevos intereses de los Estados Unidos en el Hemisferio Occidental. Año XII, $\mathrm{N}^{\circ}$ 49 (enero-marzo, 1980).

LunA, Julio. El desarrollo pesquero y la integración regional. Año IV, $\mathrm{N}^{\circ} 14$ (julioseptiembre, 1970).

MARCELLA, Gabriel. Las relaciones militares entre los Estados Unidos y América Latina. Crisis e interrogantes futuras. Año X.III, $\mathrm{N}^{\circ}$ 51 (julio-septiembre, 1980).

MARTINS, Luciano. Mayo de 1968: una revolución nueva e intransitiva. Año III, $\mathrm{N}^{\circ} 10$ (julio-septiembre, 1969).

MATTERLAR'T, Armand. La dependencia de los medios de comunicación de masas en Chile. Año IV, NNo 13 (abril-junio, 1970).

MAYOBRe, Eduardo, HuRTAdo, Héctor y PAzos, Javier. El Caribe y Venezuela: integración de la integración. Año $\mathrm{V} I \mathrm{~N}, \mathrm{~N}^{\circ} 27$ (julio-septiembre, 1974).

MERLINI, Cesare. La posición internacional deItalia. Oportunidades y tentaciones. Año V, $\mathrm{N}^{\circ} 17$ (enero-marzo, 1972).

Minaly, Eugene B. La estrategia de los Estados Unidos en el Pacifico Occidental y el dilema de Micronesia. Año v, $\mathrm{N}^{\circ} 17$ (enero-marzo, 1972).

Millar, T.B. Los Océanos Indico y Pacífico: Algunas consideraciones estratégicas. Año III, $N^{\circ}$ II (octubre-diciembre, 1969).

Mirski, Gueorgui. El papel politico del ejército en los paises de Asiay Africa. Año IV, $\mathrm{N}^{\circ}$ 13 (abril-junio, 1970).

MoLLs, Manfred. Observaciones europeas sobre la integración latinoamericana. Año XIIt, $N^{\circ} 51$ (julio-septiembre, 1980). 
MONETA, Juan Carlos. Argentina y Australia: Esquemas para la cooperación. Año VI, $\mathrm{N}^{\circ} 21$ (enero-marzo, 1973).

Africa y los grandes actores extermos. Año VII, $\mathrm{N}^{\circ} 27$ (julio-septiembre, 1974).

MONE'A, Carlos J. América Latina y el sistema internacional en la década del ochenta: ¿Hacia un nuevo orden antártico? Año XIII, No 52 (octubre-diciembre, 1980).

MORAN, Theodore H. Nuevo trato a las materias primas. Año $\mathrm{V}, \mathrm{N}^{\circ} 10$ (julioseptiembre, 1972).

MORELLo, Jorge y otro. Notas sobre la historia ecológica de América Latina. Año xili, $N^{\circ} 49$ (enero-marzo, 1980).

MuÑoz, Heraldo y Walter, SÁNCHEZ. La Détente y el Sistema Internacional. Año vIIt, No 32 (octubre-diciembre, 1975).

MuÑoz, Heraldo. Dependencia estratégica y no-estratégica: materias primas y relaciones

- en la perspectiva de la crisis petrulera. Año IX, No 33 (énero-marzo, 1976).

Cambio y continuidad en el debate sobre la dependencia. $\mathrm{N}^{\circ} 44$ (octubre-diciembre, 1978).

Los estudios-internacionales en A mérica Latina: problemas fundamentales. Año XIII, $N^{\circ} 51$ (julio-septiembre, 1980).

MURPHY, Cornelius F. Jr. Coacción económica y' tratados desiguales. Año IV, $\mathrm{N}^{\circ} 14$ (julio-septiembre, 1970).

Naudon, Carlos. Cinco libros sobre Israel. Año II, $N^{\circ} 6$ (julio-septiembre, .1968).

NiEkERK, Arnold van. La pendiente de la dependencia: una versión desde afuera. Año v, $N^{\circ} 18$ (abril-junio, 1972). América Latina y las Antillas Neerlandesas. Año vı, $N^{\circ} 23$ (julio-septiembre, 1973). La sociología latinoamericana: un testimonio epistemológico. Año $\mathrm{t}, \mathrm{N}^{\circ} 36$ (septiembre-diciembre, 1976).

OGELSBY, J.C.M. Relaciones canadienselatinoamericanas, pasadas, presentes y futuras. Año v, No 18 (abril-junio, 1972).

OLDFELT, Karin. Estudio comparativo sobre zonas pesqueras en el mundo. Año IV, $\mathrm{N}^{\circ}$ 13 (abril-junio, 1970).
Orrego Vicuña, Francisco. Dilema en el Grupo Andino. Año 111, N 11 (octubrediciembre, 1969).

Algunos problemas de derecho internacional planteados por la nacionalización de la industria del cobre en Chile. Año v1, No 24 (octubre-diciembre, 1973).

De la crisis de la energía al concepto del patrimoio económico de la humanidad: criterios para reestructurar el sistema económico internacional. Año vili, $\mathrm{N}^{\circ} 2$ (octubrediciembre, 1975).

Las alternativas de América Latina como clase media de las naciones. Año X, $\mathrm{N}^{\circ} 40$ (octubre-diciembre, 1977).

Legislación unilateral para la explotación de los fondos marinos: su incompatibilidad con el Derecho Internacional. Año X11, $\mathrm{N}^{\circ}$ 47 (julio-septiembre, 1979).

Orrego, Francisco. Europa y América Latina: ¿hacia un rol internacional complementario? Año XIV, $N^{\circ} 53$ (enero-marzo, 1981).

Ortiz MENA, Antonio. Las relaciones económicas entre América Latina y la OCED: nuevas perspectivas. Año XII, $N^{\circ} 46$ (eneromarzo, 1979).

ORTIz, Eduardo. Las grandes potencias y la crisis de Nigeria. Año 1II, N 9 (abriljunio, 1960).

Palma, Pedro. A. Análisis del Sistema Monetario Internacional. An̄o VıII, $\mathrm{N}^{\circ} 32$ (octubre-diciembre, 1975).

Palma Vicuña Ignacio. Aportes para un análisis de la crisis chilena. Año VII, $\mathrm{N}^{\circ} 26$ (abril-junio, 1974).

Pazos, Javier, Héctor HurTado y Eduardo MAYOBRE. El Caribe y' Venezuela: integración de la integración. Año VII, $\mathrm{N}^{\circ} 27$ (julio-septiembre, 1974).

PEN̄A, Félix. El Grupo Andino: un nuevo enfoque de la participación internacional de los paises en desarrollo. Año VI, $\mathrm{N}^{\circ} 22$ (abril-junio, 1973).

Tendencia y perspectivas de la integración económica en América Latina. Año VIII, $\mathrm{N}^{\circ} 29$ (enero-marzo, 1975). 
PÉrez LlanA, Carlos E. América Latina y los paises no alineados. Año vr, $\mathrm{N}^{\circ} 24$ (octubre-diciembre, 1973).

¿Potencias intermedias o países mayores? La política exterior de Argentina, Brasil y México. Año virl, $\mathrm{N}^{\circ} 29$ (enero-marzo, 1975).

El legado de Henr' Kissinger: algunas implicancias. Año x, $\mathrm{N}^{\circ} 37$ (enero-marzo, 1977).

Perspectivas de América Latina en el Diálogo Norte-Sur. Año xIr, No 46 (abrilmarzo, 1979).

PERRY, Guillermo. Los mercados mundiales de manufacturas y la industrialización de los países en desarrollo. $\mathrm{N}^{\circ} 42$ (abril-junio, 1978).

Petras, James y RIMERnsnyder, Nelson. Los militares y la modemización del Perú. Año IV, No 13 (abril-junio, 1970).

PETRAS, James. Venezuela: una década de de mocracia capitalista. Año IV, $\mathrm{N}^{\circ} 15$ (octubre-diciembre, 1970).

PINTo, Aníbal. Relaciones económicas entre América Latina y Estados Unidos: Implicaciones y perspectivas políticas. Año VI, $\mathrm{N}^{\circ}$ 22 (abril-junio, 1973).

PREBISCH, Raúl. El nuevo orden econbmico internacional, contradicciones del sistema centroperiferia. $\mathrm{N}^{\circ} 43$ (julio-septiembre, 1978).

RAMESH, Jairam y otros. Programas de energía nuclear en el mundo en desarrollo: su fundamento e impacto. $\mathrm{N}^{\circ} .49$ (eneromarzo, 1980).

RIBEIRO, Darcy. El desafio de la marginalidad. Año IV, No 16 (enero-marzo, 1971).

Nuevos caminos de la Revolución Latinoamericana. Año v, $\mathrm{N}^{\circ} 18$ (abril-junio, 1972).

Rosrow, W.W. Cómo romper la impasse en las negociaciones económicas multilaterales Norte-Sur. Año XII, $N^{\circ} 45$ (eneromarzo, 1979).

Rusell, Roberto G. y Carballal, Teresa. América Latina ¿̇hacia qué nuevo orden internacional? Año XII, No 46 (abriljunio, 1979).
RUSELL, Roberto y otros. El nuevo orden económico internacional: tendencias observables en el Norte y en los países majores de América Latina. Año XIv, $N^{\circ} 53$ (eneromarzo, 1981).

SÁBAT̃o, Jorge A. Energía Atómica en Argentina. Año II, $N^{\circ} 7$ (octubre-diciembre, 1968).

El cambio tecnológico necesario y posible. Año IX, N 36 (septiembre-diciembre, 1976).

El plan nuclear brasilero y la bomba atómica. $N^{\circ} 41$ (enero-marzo, 1978).

Programas de energía nuclear en el mundo en desarrollo: su fundamento e impacto. $\mathrm{N}^{\circ}$ 49 (enero-marzo, 1980).

SẢBATO, Jorge A. y otros. ¿ZCooperación para el desarrollo complementario? Año XIV, $\mathrm{N}^{\circ}$ 53 (enero-marzo, 1981).

SACHS, Ignacy. Ecodesarrollo: un aporte a la definición de estilos de desarrollo para América Larina. Año VII, $N^{\circ} 25$ (eneromarzo, 1974).

SAGASTI, Francisco R. Autodependencia tecnológica y cooperación entre los países del Tercer Mundo. Año IX, $\mathrm{N}^{\circ} 33$ (eneromarzo, 1976).

Políticas de ciencias y tecnología para el desarrollo. $N^{\circ} 49$ (enero-marzo, 1980).

SAGASTI, Francisco y Guerrero, Mauricio. Situación de la ciencia y tecnología en América Latina. Año vil, $\mathrm{N}^{\circ} 25$ (eneromarzo, 1974).

SAlGAdo, Germánico. Integración, conciliación de politica y' diferencias de estructura económica. Año $\mathrm{x}, \mathrm{N}^{\circ} 38$ (abril-junio, 1977).

Discurso pronuciado con motivo de la celebración del día de las Naciones Unidas en Santiago el día 24 de octubre de 1980. Año $\mathrm{XIV}, \mathrm{N}^{\circ}$ 53. (enero-marzo, 1978).

Sampaio Malain, Pedro. Las relaciones económicas internacionales de Brasil: notas para una agenda de investigación. $\mathrm{N}^{\circ} 41$ (enero-marzo, 1978).

SANCHEZ, Walter y MuÑoz, Heraldo. La Détente y' el Sistema Internacional. Año VIII, $N^{\circ} 32$ (octubre-diciembre, 1975). 
SȦNCHEZ, Walter. El Triángulo WashingtonMoscú-P ekín y el proceso de distensión internacional. Año $1 \mathrm{x}, \mathrm{N}^{\circ} 35$ (julioseptiembre, 1976).

SATHYAMURTHY, T.V. Las relaciones internacionales asiáticas: perspectivas contemporáneas. Año IV, $\mathrm{N}^{\circ} 15$ (octubrediciembre, 1970).

SCHMrTter, Philippe C. La portugalización de Brasil. Año v, $N^{\circ} .19$ (julioseptiembre, 1972).

SEPÚlvEDA, Alberto. El militarismo desarrollista en América Latina. Año IV, $\mathrm{N}^{\circ} 15$ (octubre-diciembre, 1970).

SEWELL, John. El crecimiento del Norte. ¿Es posible sin el progreso del Sur? $\mathrm{N}^{\circ} 42$ (abril-junio, 1978).

Sigmund, Paul E. El bloqueo invisible y la caída de Allende. Año vu, $\mathrm{N}^{\circ} 26$ (abriljuniQ, 1974).

SILVA CASTro, Räúl. Juan Egaña, precursor de la integración latinoamericana. Año II, $\mathrm{N}^{\circ} 7$ (octubre-diciembre, 1968).

Silva Michelena, José A. Tendencias recientes en la política mundial. Año V1, $\mathrm{N}^{\circ}$ 23 (julio-septiembire; 1973).

SNOW, Peter G. Desarrollo económico y Seguridad Nacional en el Régimen Militar Argentino. Año $v ; N^{\circ} 20$ (octubrediciembre, 1972).

Sunkel, Osvaldo. Polititica nacional de desamollo y dependencia exterria. Año $\mathrm{I}, \mathrm{N}^{\circ} 1$ (abril, 1976).

La tarẹa política y teórica del planificador en Américia Latina. Año II, $\mathrm{N}^{\circ} 8$ (eneromarzo, 1969).

Esperando a Godot: América Latina ante la nueva administración republicana de los Estados Unidos. An̄o III, $N^{\circ} 9$ (abriljunio, 1969).

La Universidad Latinoamericana ante el avance científico y técnico; algunas reflexiones. Año IV, $N^{\circ} 13$ (abril-junio, 1970).

Capitalismo transnacional y desintegración nacional en América Latina. Año IV, $\mathrm{N}^{\circ}$ 16 (enero-marzo, 1971).

El desarrollo de la teoría del desarrollo. Año X, $\mathrm{N}^{\circ} 40$ (octubre-diciembre, 1977).
Sunkel, Osvaldo, Luclano, Tomassini. La crisis del sistema transnacional y el cambio en las relaciones internacionales de los países en desarrollo. $N^{\circ} 50$ (abril-junio, 1980).

SUNKEL, Osvaldo y FuENZALIDA; Edmundo. Capitalismo transnacional y desarrollo nacional. $\mathrm{N}^{\circ} 44$ (octubre-diciembre, 1978).

TADIC, Bojana. No-alineación: un vistazo histórico y' conceptual. Año III, $N^{\circ} 10$ (julioseptiembre, 1969).

TeITElbolm, Sergio. Ĺos países del Pacifico Sur y el mar territorial. Año IV, $\mathrm{N}^{\circ} 13$ (abril-junio, 1970).

Thomas, Hugh. La Revolución Cubana y sus raíces históricas. Año IV, No 16 (enero-. marzo, 1971).

Thompson, James C. Jr. Vietnam: un caso clínico. Año Ir, $N^{\circ} 7$ (octubre-diciembre, 1968).

TIRONI, Ernesto. Las estrategias nacionales de desarrollo y la integración de los Paises Andinos. Año IX, $\mathrm{N}^{\circ} 34$ (abril-junio, 1976).

La Decisión 24 sobre capitales extranjeros en el Grupo Andino. Año x, № 38 (abriljunio, 1977).

Tomassini, Luciano. La misión imposible del presidente Nixon. Año IV, $\mathrm{N}^{\circ} 12$ (eneromarzo, 1970).

Implicaciones internacionales del deterioro ecológico. Año v, N 18 (abril-junio, 1972).

Tendencias favorables o adversas a la formación de un sistema regional latinoamericano. Año VIII, $\mathrm{N}^{\circ} 29$ (enero-marzo, 1975).

Falencias y falacias: notas sobre el estudio de las relaciones Norte-Sur. Año X, $\mathrm{N}^{\circ} 40$ (octubre-diciembre, 1977).

Intereses mutuos: las verdaderas bases del diálogo Norte-Sur. $\mathrm{N}^{\circ} 41$ (enero-marzo, 1978).

El nuevo orden internacional: varios enfoques. Año xir, $N^{\circ} 46$ (abril-junio, 1979). 
Tomassini, Luciano y Osvaldo, Sunkel. La crisis del sistema transnacional y el cambio en las relaciones internacionales de los países en desarrollo. $\mathrm{N}^{\circ} 50$ (abril-junio, 1980).

Los estudios internacionales en América Latina: algunas contribuciones. Año XIII, $\mathrm{N}^{\circ}$ 52 (octubre-diciembre, 1980).

TORRES-Rivas, Edelberto. Desarrollo, integración y dependencia en Centroamérica. Año 1V, No 12 (enero-marzo, 1970).

TOYNBEE, Arnold. El estudio de la historia contemporánea. Año I, $\mathrm{N}^{\circ} 1$ (abril, 1967).

TULCHIN, Joseph S. Una perspectiva histórica de la política argentina frente al Brasil. Año xIII, $N^{\circ} 52$ (octubre-diciembre, 1980).

Ullman, Richard. Seguridad internacional en los años ochenta. $\mathrm{N}^{\circ} 50$ (abril-junio, 1980).

USLAR PIETRI, Arturo. Lo específico del hombre latinoamericano. Año $\mathrm{IX}, \mathrm{N}^{\circ} 36$ (septiembre-diciembre, 1976).

VALDÉs SUBERCASEAUX, Gabriel. Siluación del Grupo Andino en el contexto latinoamericano $e$ internacional. Año $\mathrm{x}, \mathrm{N}^{\circ} 38$ (abril-junio, 1977).

VAN DAM, André. El triunfo del caballo. Año IX, No 34 (abril-junio, 1976).

VARGAS HIDALGo, Rafael, Estados Unidos y América Latina bajo la presencia de Carter. $N^{\circ} 41$ (enero-marzo, 1978).

VÉLIZ, Claudio. ElInstituto de Estudios Internacionales. Año i, No 1 (abril, 1967). Centralismo, Nacionalismo e Integración. Año un, $N^{\circ} 9$ (abril-junio, 1969). Cambio y continuidad: El Pacto Andino en la historia contemporánea. Año IV, $\mathrm{N}^{\circ} 16$ (enero-marzo, 1971).

Errores y omisiones: notas sobre la política exterior de los países de América Latina durante los últimos diez años. Año $\mathrm{X}, \mathrm{N}^{\circ} 40$ (octubre-diciembre, 1977).

La tradición centralista en América Latina. $\mathrm{N}^{\circ} 50$ (abril-junio, 1980).
VERNANT, Jacques. El mundo, Europa y Francia. Año I, $N^{\circ} 2$ (julio, 1967).

VILAS, Carlos María y AcosTA, Mercedes. Santo Domingo y Checoslovaquia en la politica de bloques. Año $11, \mathrm{~N}^{\circ} 8$ (eneromarzo, 1969).

Villalba Vera, Jovito A., Claverie Ro. DRiguez, Eliodoro L. y ECHEVERRIA, Pedro Luis. ElTratado modificado de reciprocidad comercial entre Venezuela y los Estados Unidos. Año v, $\mathrm{N}^{\circ} 19$ (juliodiciembre, 1972).

VILLAMIL, José. El proceso de transnacionalización en el caso del Caribe. $\mathrm{N}^{\circ} 44$ (octubre-diciembre, 1978).

VILLAGRÁN KRAMER, Francisco. Mecanismos de regulación internacional de productos básicos. Año vi, $\mathrm{N}^{\circ} 23$ (julioseptiembre, 1973).

WALLIS, Víctor. La experiencia de Brasil con. una política exterior independiente. Año $\mathrm{I}_{\text {, }}$ $N^{\circ} 2$ (julio, 1967).

WARD, Bárbara. Perspectivas históricas del nuevo orden económico internacional. $\mathrm{N}^{\circ}$ 42 (enero-marzo, 1978).

WaTKINS, Melville H. Canadá: industria y propiedad extranjera. Año $11, \mathrm{~N}^{\circ} 10$ (julio-septièmbre, 1969).

WERTHEIM, W.F. Indonesia antes y después del golpe de Untung. Año 1, $N^{\circ} 3$ (octubre, 1967-marzo, 1968).

WILHELMY, Manfred. La política exterior chilena en el Grupo Andino. Año X, $\mathrm{N}^{\circ} 38$ (abril-junio, 1977).

La política exterior de los Estados Unidos dinámica interna y nuevos problemas. $\mathrm{N}^{\circ}$ 42 (abril-junio, 1978).

Hacia un análisis de la politica exterior chilena contemporánea. Año XIII, $\mathrm{N}^{\circ} 48$ (octubre-diciembre, 1979).

YOUNGER, Kenneth. El papel de Gran Bretaña en la política internacional. Año $1, N^{\circ} 2$ (julio, 1967).

ZEgers SANTA CRUZ, Fernando. El sistema antártico y la cuestión del aprovechamiento de los recursos en el ärea. Año Xil, $\mathrm{N}^{\circ} 47$ (julio-septiembre, 1979). 